prevalence was not significantly influenced by work stress. The results support the association between subjective symptoms and EMF exposure in MRI operators. Another conclusion is that the appearance of the specific group of 'core symptoms' may be usefully investigated in health surveillance of MRI operators.

\section{0 b PROTECTION OF MRI WORKERS AGAINST MAGNETIC FIELDS ACCORDING TO EU DIRECTIVE AND ICNIRP GUIDELINES}

${ }^{1} \mathrm{GM}$ Contessa, ${ }^{2} \mathrm{D}$ Andreuccetti, ${ }^{3} \mathrm{R}$ Falsaperla, ${ }^{1} \mathrm{~V}$ Lopresto, ${ }^{1} \mathrm{R}$ Pinto, ${ }^{4} \mathrm{~A}$ Polichetti, ${ }^{2} \mathrm{~N}$ Zoppetti. ${ }^{1}$ Centro Ricerche Casaccia - ENEA, Rome, Italy; ${ }^{2}$ Istituto di Fisica Applicata 'Nello Carrara' (IFAC-CNR), Sesto Fiorentino (Florence), Italy; ${ }^{3}$ Dipartimento di Medicina, Epidemiologia, Igiene del Lavoro ed Ambientale - INAIL, Rome, Italy; ${ }^{4}$ Centro Nazionale per la Protezione dalle Radiazioni e Fisica Computazionale - ISS, Rome, Italy

\subsection{6/oemed-2018-ICOHabstracts.1208}

Introduction Directive 2013/35/EU lays down minimum health and safety requirements regarding the exposure of workers to electromagnetic fields, including those present in Magnetic Resonance Imaging (MRI) facilities. For what concerns the Static Magnetic Field (SMF), the Directive follows a 'flexible approach' introduced by the 2009 ICNIRP guidelines, which is based on the distinction between sensory and health effects, thus allowing in some circumstances exposed workers to possibly experience unpleasant sensory effects. In addition, the Directive provides for the possibility of derogating from the health exposure limits, explicitly referring to the case of MRI. However, protection issues related to effects associated with movements of workers in the SMF are not completely addressed by EU limits. ICNIRP has published a guideline on this matter in 2014, but it has not yet been transposed into the Directive.

Methods Measurements were performed of low frequency switched gradient magnetic fields and of the magnetic flux density experienced as variable by workers moving in the SMF of $1.5 \mathrm{~T}, 3 \mathrm{~T}$ and $7 \mathrm{~T}$ MRI scanners. In the latter case, three different metrics were applied to process the collected data and compare them with the EU Directive Exposure Limit Values (ELVs) for SMF, the ICNIRP basic restrictions (BRs) aimed at preventing vertigo effects and the ICNIRP reference levels (RLs) intended to prevent stimulation effects.

Results Regarding movement in the SMF, reported values of the peak magnetic flux density, of its variation in $3 \mathrm{~s}$ and of the weighted-peak indices for stimulation effects show several cases of non-compliance with the corresponding ICNIRP BRs and RLs even when EU Directive ELVs are complied with. Results of exposure to low frequency magnetic fields are being processed.

Acknowledgments part of the work presented is funded by INAIL, Italian Workers' Compensation Authority.

\section{C PREVENTION OF ELECTROMAGNETIC EXPOSURE OF WORKERS NEAR MRI SCANNERS - 25 YEARS OF EXPERIENCE IN POLAND}

J Karpowicz, K Gryz. Central Institute for Labour Protection - National Research Institute, Warszawa, Poland
Introduction Inside the diagnostic chamber of magnetic resonance imaging (MRI) scanners, every worker (medical personnel, cleaners, administrative, etc.) is affected by the strong static magnetic field (SMF) emitted continuously by superconducting magnets (24 hours per day).

Methods A retrospective study on the variety of parameters characterising the static and dynamic influence of SMF (B-field level and spatial distribution, spatial gradients $(\mathrm{dB} / \mathrm{dx})$, dynamic changes of exposure caused by body movements $(\mathrm{dB} /$ $\mathrm{dt})$ ) covered their analysis based on the results of our 25-yearlong investigations into the context of the development of scanner design, work practice, requirements of occupational legislation and an understanding of the nature of health and safety hazards.

Results We found significant variability in the exposure pattern, and that exposure parameters may not be proportional to the magnet power, but may be highly dependent on the scanner design. It suggests the potential to reduce worker exposure by ergonomic and organisational interventions.

Conclusion Our extensive studies on workers' SMF exposure near MRI scanners has shown that the set of SMF action levels $(0.5,3,50,200,400 \mathrm{mT} ; 1,2,8 \mathrm{~T})$ may sufficiently characterise various hazards caused by the static and dynamic influence of SMF on workers and various objects. The threedimensional mapping of SMF distribution near MRI magnets, and its graphical representation in the diagnostic room, provides significant practical information for managers and workers in the MRI centre, leading to an understanding of how to develop the work practice in order to reduce daily exposure to SMF.

Research supported in Poland by the Ministry of Family, Labour and Social Policy - the National Programme 'Improvement of safety and working conditions' (project 1 .G.12).

\section{SOLAR UV: A RELEVANT OCCUPATIONAL RISK OVERLOOKED. EXPOSURE IN WORKERS, EFFECTS, PREVENTION}

Fabriziomaria Gobba. University of Modena and Reggio Emilia, Modena, Italy

\subsection{6/oemed-2018-ICOHabstracts. 1210}

Aim of special session The exposure to Solar UV Radiation is a significant risk factor in several occupational activities and the adverse health effects induced in exposed workers, mainly to the skin and to the eye, are relevant, frequent and well documented. Nevertheless, we have to admit that this important occupational risk is usually underestimated, if not ignored. On the contrary, the development of adequate preventive measures represents a priority in OHS. Objective of this Special Session is an update on the results on exposure evaluation, adverse effects and enforceable prevention strategies in exposed workers

Presenters March Wittlich ${ }^{1}$, Pietro Sartorelli ${ }^{2}$, Swen Malte $\mathrm{John}^{3}$, Alberto Modenese ${ }^{4}$, Peter Connaughton ${ }^{5}$, Shengli Niu ${ }^{6}$

${ }^{1}$ Institute for Occupational Safety and Health (IFA), Sankt Augustin, Germany

${ }^{2}$ Unit of Occupational Medicine AOU Senese, Department of Medical Biotechnology, University of Siena, Siena, Italy

${ }^{3}$ Department of Dermatology, Environmental Medicine, Health Theory - Faculty of Human Sciences, University of Osnabrueck, Osnabrueck, Germany

${ }^{4}$ University of Modena and Reggio Emilia, Modena, Italy 